\title{
Petjades de la prostitució a la literatura: el cas de l'Espill de Jaume Roig Antònia Carré
}

Ja sabem quin és l'ofici més vell del món... en tenim exemples bíblics, testimonis de l'antiguitat grega i romana, de l'Edat Mitjana... i així, fins arribar al segle XXI. L'ofici ha existit des de sempre i des de sempre que hi ha hagut intents per regular-lo, per mantenir-lo dins de les pautes de la llei. Encara que això hagi comportat l'exercici d'una doble moral: d'una banda, l'imaginari collectiu condemna moralment l'ofici i les dones que l'exerceixen, però, de l'altra, sent alguna mena de fascinació pel descontrol del desig i per les fantasies de plaer que ofereixen determinats indrets prohibits. Òbviament, tot això ha tingut repercussions literàries en totes les èpoques. Centrem-nos, però, en l'Edat Mitjana i pensem per un moment en alguns personatges dels fabliaux

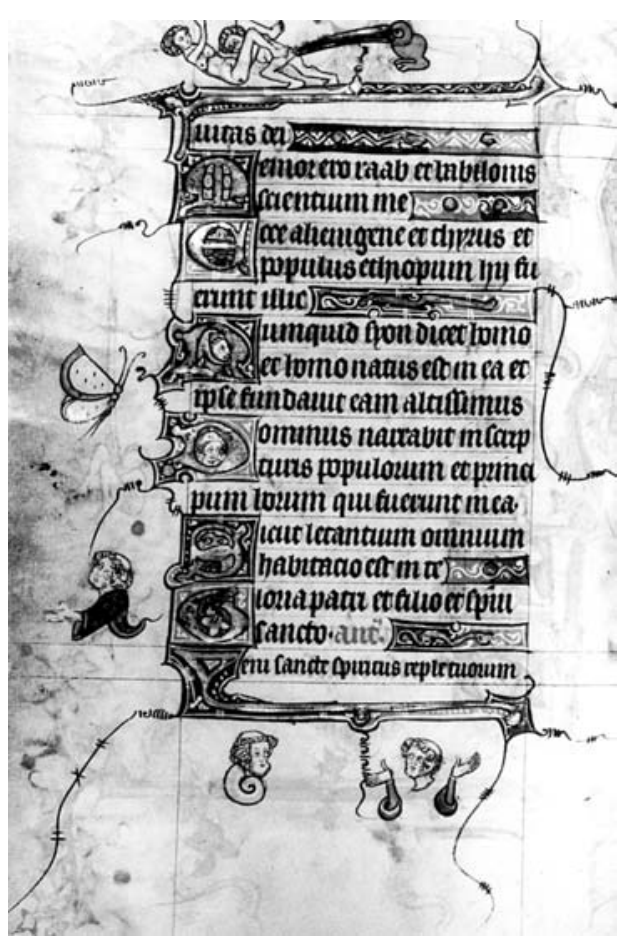

Escena sexual al marge d'un llibre d'hores (Nova York, Pierpoint Library). -els «contes per riure en vers» basats moltes vegades en la seducció i la sexualitat-, en algunes de les històries del Decameron de Giovanni Boccaccio, en els Contes de Canterbury de Geoffrey Chaucer o en La Celestina de Fernando de Rojas. L'aparició del món de la prostitució en totes aquestes obres té molt a veure, com és natural, amb la realitat de l'època.

A l'Edat Mitjana, tant les autoritats civils com les religioses acceptaven la prostitució com un fet necessari, imprescindible per vehicular ordenadament la sexualitat masculina i, alhora, per protegir les dones decents de l'agressivitat desbocada dels mascles (Flan- drin 1984: 31 |-321). Ho podem constatar en les obres de moralistes o predicadors com Francesc Eiximenis o sant Vicent Ferrer, que ho declaren sense embuts. El menoret gironí, per exemple, té un capítol en la seva enciclopèdia Lo crestià amb un títol prou explícit: «Per què la santa Esgleia e los prínceps sostenen les fembres públiques?».' Tenim documentada la participació d'individus joves (un de cada dos!) en violacions col·lectives, que constituien una mena de ritual iniciàtic al món de la virilitat. Les dones agredides eren de diversa condició: una viuda jove, una donzella a punt de casar-se, una serventa, una esposa amb el marit lluny, una prostituta... mentre que els agressors podien pertànyer als estaments socials més benestants (Rossiaud 1986: 29-30; Viciano 2005: 333). A Castelló de la Plana, posem per cas, cinc joves van participar en una brutal violació col·lectiva d'una dona «pública e mundària» el |49|. Els cinc joves en qüestió no pertanyien a un ambient marginal, sinó que tenien un ofici reconegut - dos eren ferrers i un altre llaurador - o eren fills de famílies que contribuïen al govern de la vila (Viciano 2005: 346). Davant d'aquest estat de coses, les autoritats de les ciutats de l'Europa llatina occidental van entendre de

I. Viciano (2005: 330-33I), amb altres referències d'Eiximenis i sant Vicent Ferrer. 


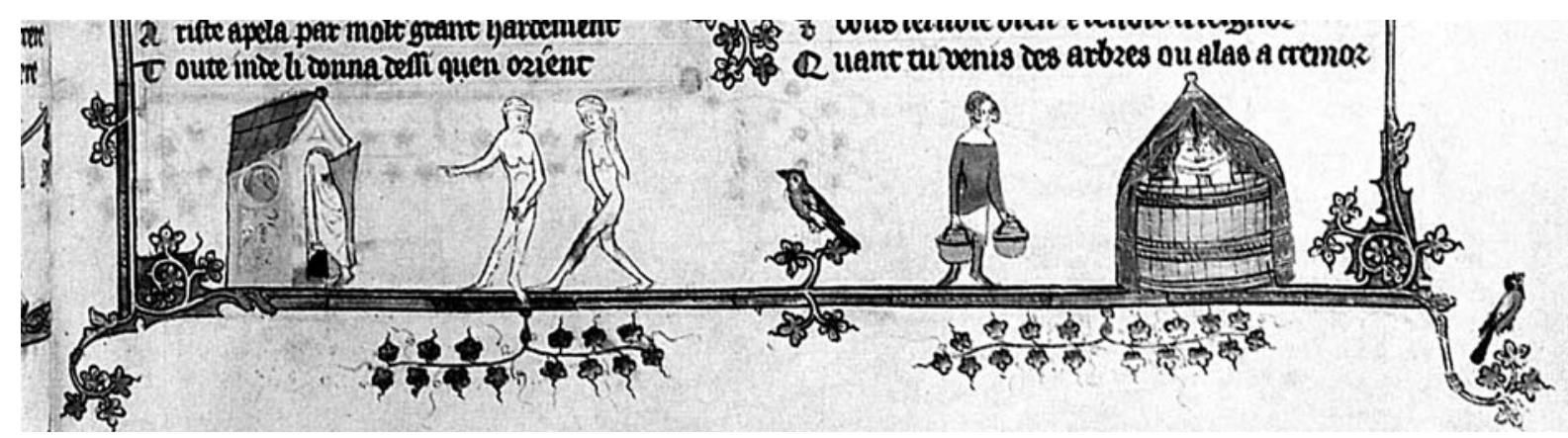

seguit que s'havien de canalitzar pulsions sexuals tan violentes i aquest va ser un dels motius que els va induir a crear els prostíbuls municipals a començaments del segle XIV. Certament, la majoria de les ciutats medievals tenien un prostibulum publicum, construit, mantingut i regentat per les autoritats municipals perquè s'havien adonat que la prostitució era tan essencial com les clavegueres. ${ }^{2}$

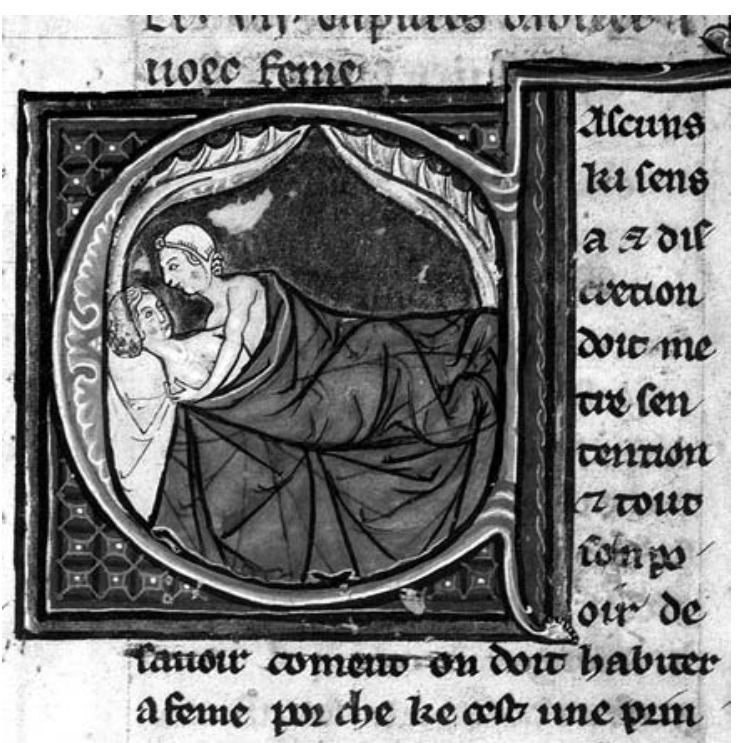

Els regiments de sanitat dedicaven uns capítols a les relacions sexuals, beneficioses per a la salut (Regiment del cos d'Aldobrandino de Siena, Londres, British Library).

A més del seu bordell públic, les ciutats tenien altres cases de tolerància sexual, com ara els hostals on es reunien els veïns als vespres per beure o jugar als daus o a cartes (Viciano 2005: 340-343) i els banys, que eren

2. Seguint sant Agustí, sant Tomàs d'Aquino desenvolupa en la Summa teològica el principi de tolerància envers la prostitució. $\mathrm{Al}$ segle XIII es va popularitzar una glossa en aquest text que deia que «la dona pública és a la societat el que la sentina és al mar i la claveguera al palau. Treu la claveguera i tot el palau quedarà infectat.» (Rossiaud 1986: 102).
Els banys urbans representats com a bordell (Roman d'Alexandre, Oxford, Bodleian Library).

freqüentats per diferents estaments socials amb la finalitat de mantenir la higiene corporal i de preveure o guarir algunes malalties, però també amb la intenció de dur-hi a terme intercanvis econòmics, socials o amorosos (Carré i Cifuentes, en premsa). La història de Flamenca, la bella novel·la occitana escrita a finals del segle XIII, n'és una bona mostra: ambientada en una zona rica en aigües termals, els banys públics són l'escenari on té lloc l'adulteri entre la protagonista i el seu cavaller enamorat, Guillem de Niviers.

Les prostitutes formaven part de determinats àmbits de la vida masculina amb naturalitat, encara que algunes veus manifestessin la seva disconformitat amb una tal relaxació de costums. Les autoritats acceptaven que les dones que venien el seu cos s'embarquessin en les naus dels corsaris o que acompanyessin els exèrcits (Vinyoles 2005: 222), però aquesta permissivitat no estava exempta de polèmica. El trobador Bertran de Born, per exemple, que és el que millor ha descrit l'escenografia de les batalles en els seus versos, rebutja les males companyies que anaven de bracet amb els soldats que havien de fer la guerra. Com recorda Asperti (2005: 54), ho diu en els versos 25-32 del sirventès «Ar ve la coindeta sazos», escrit el I | 94 per celebrar el retorn de Ricard Cor de Lleó a les seves terres després d'un llarg empresonament a Àustria:

No.m platz companha de basclos

ni de las putanas venaus.

Sacs d'esterlis e de moutos

m'es laitz, quan son vengut de fraus.

E maisnadier eschars deuria om pendre

e ric ome, quan son donar vol vendre.

En domn'escharsa no.s deuria om entendre

que per aver pot pleiar e estendre.

(Riquer 1975: II, 732) 
[No m'agrada la companyia de robadors ni de les putes venals. Em desagraden els sacs d'esterlines i de moltons, quan procedeixen del frau. El capità mesquí hauria de ser penjat i també el ric home quan vol vendre la seva generositat. I hom no s'hauria d'entendre amb una dama avara que es deixa dominar i s'ajeu per diners.]

\section{Unes pinzellades del tema a la Corona d'Aragó}

A la Corona d'Aragó trobem les primeres normes escrites sobre els bordells al segle XIV. El rei Alfons el Benigne deia en una carta enviada als prohoms de Barcelona el 1330 que les dones vils no podien viure en el mateix veïnat que les honestes, sinó que havien de tenir les seves pròpies cases (Vinyoles 2005: 217). Les ordenances municipals van delimitar l'indret d'una ciutat on s'havien d'establir els prostíbuls, que en les ciutats grans del sud d'Europa ocupaven diversos carrers i edificis, com ara hostals, tavernes i cases. Tenim documentat el bordell de València, que ocupava tres o quatre carrers a l'indret conegut com la pobla de Bernat Villa, un barri situat al nord de la moreria que estava separat de les muralles per un ramal delTúria. Aquí és on Jaume II havia ordenat de traslladar totes les meretrius l'any 1325 (Narbona 1992: 164- 167). Sabem que a Barcelona el prostíbul més antic es trobava al carrer de Viladalls, que era proper a l'actual Plaça Reial. Més tard, a finals del segle XIV, se'n va instal $\cdot$ lar un altre a la Volta d'en Torra, entre els actuals carrers de Tallers i del Carme, i al segle XV n'hi havia un altre prop del portal de Sant Daniel (Vinyoles 2005: 2 I8). I coneixem les vicissituds del bordell de Castelló de la Plana, documentat extramurs des del |40I (Viciano 2005: 334).

La vinculació directa de les autoritats municipals amb el prostíbul de les ciutats medievals s'establia a través de l'hostaler del bordell, que era la persona encarregada de donar allotjament, menjar i roba a les dones que hi treballaven a canvi d'un arrendament. Els preus que cobraven les dones estaven controlats pel municipi (Viciano 2005: 338). En un document de 1429, escrit a Cardona, consta que la vila paga a un tal Andreu de Casamitjana seixanta-quatre sous anuals per fer d'enterramorts - de vaser- i tenir cura del bordell, acomodar-hi les dones i proporcionar-los un llit per poder exercir la seva feina:
N'Andreu de Casamitjana de la vila de Cardona promet als honorables cònsols de la dita vila de Cardona que són l'any present, ço és en Bernat Cardona e Jaume de Mavell, Tomàs de Salavert e en Pere Çapinya, que bé e lleialment els servirà a ells e a llurs successors e a la dita vila, ço és, saber de la vaseria e tenir lo bordell, la casa que és del dit bordell en condret segons ara és, e de tenirhi i dar-hi bon recapte a les fembres e a tenir un llit per les fembres [... . E los dits honorables cònsols damunt dits donen-li per sos treballs a servitud de la dita vaseria e per tenir lo dit lit a les fembres e aquelles ésser ben servides [...] seixanta-quatre sous anuals [...] (Serra Vilaró 1962-66: II, I, 21 7-2 I 8; regularitzo l'ortografia)

De la mateixa manera que estava reglamentat l'indret on les prostitutes podien treballar, també s'estipulava que alguns dies no podien exercir la seva professió per motius religiosos. Així, com que per Setmana Santa era obligatòria la continència sexual, les prostitutes eren recloses després del dinar del dimecres sant fins acabada la missa del diumenge de Pasqua, amb totes les despeses de manutenció i llenya sufragades pel municipi. Les prostitutes de Barcelona eren portades a l'hospital de Santa Marta, que era al costat del convent de les clarisses, i després al convent de les monges egipcíaques. En ciutats més petites com ara Cervera, per Setmana Santa les prostitutes eren recloses en cases particulars amb les despeses pagades pels paers (Vinyoles 2005: 221).

Seguint la norma dels romans, que obligava les meretrius a portar un determinat vestit, a tenyir-se els cabells o a posar-se una perruca groga, la legislació medieval també establia com havien d'anar per poder ser distingides quan es relacionessin amb les dones honorables. Les autoritats cristianes volien separar-se i protegir-se així de l'alteritat i del vici. Les meuques medievals anaven adornades amb joies i vestides amb colors llampants i els estava prohibit de tapar-se amb una capa, un mantell o qualsevol altra mena d'abrigall (Vinyoles 2005: 219). La indumentària les havia d'identificar perfectament, de la mateixa manera que havia de distingir els col·lectius integrants de les dues minories religioses que formaven la societat multicultural medieval: els musulmans i els jueus. Els homes i les dones musulmans havien de portar a la part alta de la màniga, i de forma ben visible, una cinta groga de mig pam de llarg, i si el vestit que duien era groc, s'havien de posar la cinta vermella. Al 
seu torn, els jueus i les jueves tenien l'obligació de cosirse una rodella groga i vermella a l'alçada del pit (Vinyoles 2005: 2 I I). Ara bé, si analitzem més a fons el cas de les prostitutes arribarem a la conclusió, seguint l'excel·lent treball de Jacques Rossiaud, que la insígnia que lluien no només era un signe d'infàmia, sinó que també les protegia de possibles violències i abusos comesos, per exemple, per joves que volien els seus serveis sense haverlos de pagar. I és que les prostitutes, tot i que d'una banda són marginades socialment, de l'altra són acceptades perquè acompleixen una funció important. Tenim documents que proven que moltes vegades, després d'haver abandonat el bordell -on no es podien quedar més enllà de la trentena- algunes d'aquestes dones trobaven feina com a serventes i fins i tot aconseguien de casar-se (Rossiaud 1986: 49). Les donotes passaven un any de reclusió i penitència a les cases de les repenedides que hi havia per totes les ciutats, transcorregut el qual la societat considerava que havien expiat els seus pecats. Llavors els jurats els atorgaven un petit dot perquè es poguessin reintegrar a la vida ciutadana (Narbona 1992: 193-201). Al final de la seva trajectòria, doncs, hi havia bagasses que es redimien.

Sabem de l'existència d'una dona barcelonina que es deia Bordelleta -amb aquest nom podia ser perfectament una prostituta redimida-i que havia d'estar casada perquè va cometre adulteri amb un home anomenat Oliva, segurament en absència del marit. El cas es va fer famós per la Barcelona de la meitat del segle XV, com explica el jurista barceloní Joan Ramon Ferrer en la glossa que va escriure al seu propi sirventès. Perquè no li fos impedida la consumació de l'adulteri, Bordelleta va emmetzinar la seva mare amb un colom i va fer que l'esmentat Oliva i un company escanyessin el seu pare (Cabré 2002: 246, nota 53). Aquesta vegada és ben evident que la redempció de la prostituta no va tenir èxit.

\section{La prostitució a l'«Espill» de Jaume Roig}

El metge valencià Jaume Roig va redactar l'Espill cap al 1460. Són més de setze mil versos que constitueixen una ferotge diatriba contra les dones, escrita seguint la tradició romànica de les noves rimades amb una clara intencionalitat còmica, ${ }^{3}$ i que hem de situar dins del debat sobre la condició femenina que se suscita a la literatura en llengua vulgar des del segle XIII (Blamires 1992; Cantavella 1992; Archer i Riquer 1998). A banda de la seva rigorosa labor de composició i de la seva clara voluntat d'estil (Carré 1994), una de les més grans virtuts de Jaume Roig és que ha sabut reflectir en la seva obra diversos aspectes de la realitat contemporània. Efectivament, pels versos de l'Espill desfila l'animació de les places i dels carrers de la València d'aleshores, que apareixen plens dels personatges que acolorien la vida urbana: artesanes, venedores, metges i metgesses, barbers, hospitals, hostals, capellans, esglésies, monges, tornejos, convents, cavallers, bandolers, pescadors, malalties, medicaments, censos, dots, aixovars, etc., constitueixen un món bigarrat i complex que és el que es veia i es vivia a la segona meitat del segle $X V$ en qualsevol ciutat de l'Europa llatina occidental d'unes certes dimensions. En una obra d'aquestes característiques, és lògic que hi apareguin dones que es dediquen a l'ofici més vell del món. I com que Jaume Roig adopta la postura del moralista i acaba defensant que el millor que poden fer els homes és apartar-se per sempre de les dones, no ens ha d'estranyar que les prostitutes que hi surten siguin completament censurades per la seva activitat pecaminosa.

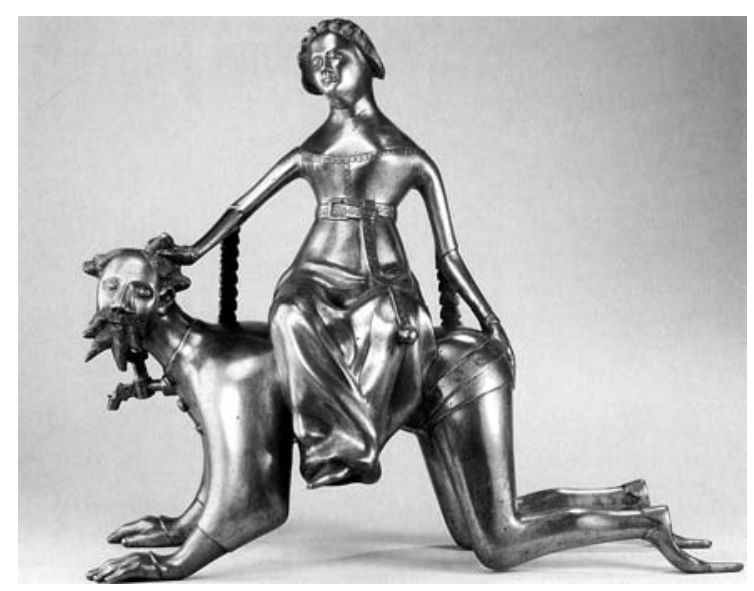

Estatueta d'Aristòtil cavalcat per una dona (Nova York, Metropolitan Museum of Art). Un dels arguments utilitzats en el debat sobre la condició femenina a la literatura és que les dones són capaces de fer cometre a un home, fins i tot al més intel-ligent, qualsevol bogeria. En aquests textos corria la llegenda que Aristòtil s'havia deixat cavalcar per una amant d'Alexandre Magne.

3. L'Espill s'ha de relacionar amb la comèdia medieval, que és un gènere definit per la presència de personatges de baix nivell, un llenguatge de to popular i una línia argumental que comença amb la desgràcia dels protagonistes i acaba amb un final feliç (Carré 2002: 371-372). 
Considerar que les dones, des dels temps d'Adam i Eva, són les úniques culpables de tots els pecats sexuals és un dels arguments més utilitzats pels antifeministes que participen en el debat sobre la condició femenina. La literatura ha condemnat les dones per això des de la sàtira VI de Juvenal, escrita entre l'any 100 i el I27. El poeta romà afirma que les dones són insaciables sexualment, i aquest és un dels molts motius que aconsellen l'home genèric de no casar-se mai. Ho diu amb un vers que ha esdevingut cèlebre: l'esposa de l'emperador Claudi, que a les nits fugia del llit imperial per anar a fer de prostituta sense que la pogués reconèixer ningú, acabava sempre a la matinada «fatigada pels homes, però no assaciada» (Juvenal 1961: I, 104).

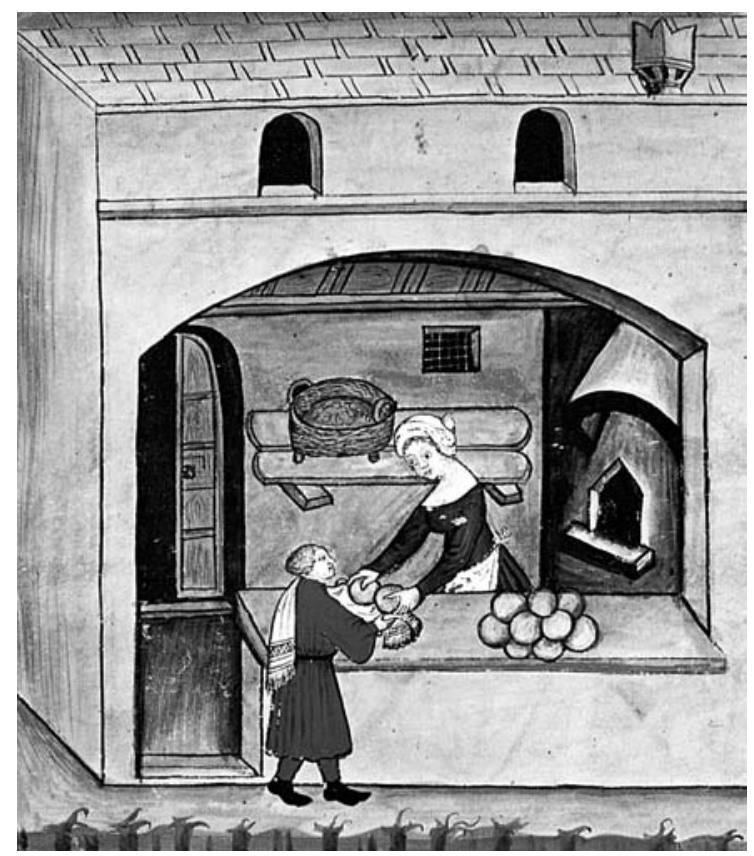

Una fornera despatxant la mercaderia al Tacuinum sanitatis (Viena, Österreische Nationalbibliothek). Les dones que exercien aquest ofici tenien fama de dur una vida dissoluta.

El primer exemple de prostitució de l'Espill és una mena de versió masculina del que representa per a Juvenal l'esposa de l'emperador Claudi. És el cas d'una fornera de Lleida, amb la qual es troba el protagonista i narrador durant el seu viatge per Catalunya, que comet la immoralitat de prostituir el seu fill, elogiat per la virilitat de què fa gala. El mascle que aquí practica el sexe per diners no és un viciós, sinó un home ple de força. El pecat recau exclusivament sobre la dona que l'incita:

\author{
En Lleyd'antrant, \\ viu roçeguar, \\ puys squarterar, \\ una fornera \\ sols per terçera \\ he conduyr \\ son fill dormir \\ ab ses loçanes \\ parroquianes \\ en l'alquavor; \\ ab gran riguor \\ l'axecutaren. \\ Lo fill soltaren \\ per en jovent \\ ser tan valent.
}

(Carré 2000: I, wv. 1074-1088)

[Entrant a Lleida, vaig veure arrossegar i després esquarterar una fornera, només per fer d'alcavota i conduir el seu fill a dormir a l'alcavor amb les seves fresques clientes. Amb gran rigor la van executar. El fill, el van deixar anar per ser tan resistent en plena joventut.]

Jaume Roig ha construit l'escena a partir de la literatura i de la realitat contemporània. La imatge de la fornera que cou el pa al forn té connotacions sexuals des de la literatura clàssica que arriben ben bé fins al segle XV, com ho demostren les cobles de «jAy, panadera!»», escrites a Castella arran de la batalla d'Olmedo ( 1445), que ridiculitzen els dos bàndols enfrontats en el conflicte, els nobles que lluitaven al costat del rei castellà Joan II, com el marquès de Santillana, i els que lluitaven al costat dels infants d'Aragó. ${ }^{4}$ D'altra banda, els documents ens proven que la prostitució de menors, estimulada o consentida per les mares, era freqüent en els medis urbans més pobres (Viciano 2005: 353). Així, ens consta l'existència d'un cavaller mallorquí el nom del qual desconeixem que vivia en una casa del Call barceloní cap al 14I0. Als baixos de l'edifici hi vivia també una viuda pobra amb la seva filla. Com que els dos

\footnotetext{
4. «Di, Panadera, / Panadera soldadera, / que vendes pan de barato, / quéntanos algún rebato / que te aconteció en la vera. / Di, Panadera. / Un miércoles que partiera / el príncipe don Enrique / a buscar algún buen pique / para su espada ropera, / saliera sin otra espera / de Olmedo tan gran compaña, / que con mui fermosa maña / al Puerto se retrujera. / Di, Panadera.» Les coples van tenir difusió a la Corona d’Aragó (Riquer 1986).
} 
habitatges es comunicaven per la porta de l'escala, el cavaller es feia pujar discretament la nena per abusarne, sembla que amb el consentiment de la mare i la promesa de donar-li un dot per poder-la casar (Batlle i Vinyoles 2002: I 28). Mai no sabrem si el cas esmentat per Jaume Roig va esdevenir-se de debò o no, però el que és remarcable és la precisió amb què s'explica i les dosis de cinisme que s'hi inclouen. La sentència contra la dona és implacable: és condemnada a morir arrossegada per terra, lligada a un animal. ${ }^{5}$ Aquest era un càstig aplicat als condemnats a mort que, si no produïa l'efecte desitjat, es completava penjant, cremant o esquarterant el reu, que és el que li passa precisament a la fornera. ${ }^{6} \mathrm{El}$ seu fill, en canvi, és elogiat per la potència sexual que demostra. El recargolament de l'episodi havia de provocar per força la rialla del públic contemporani.

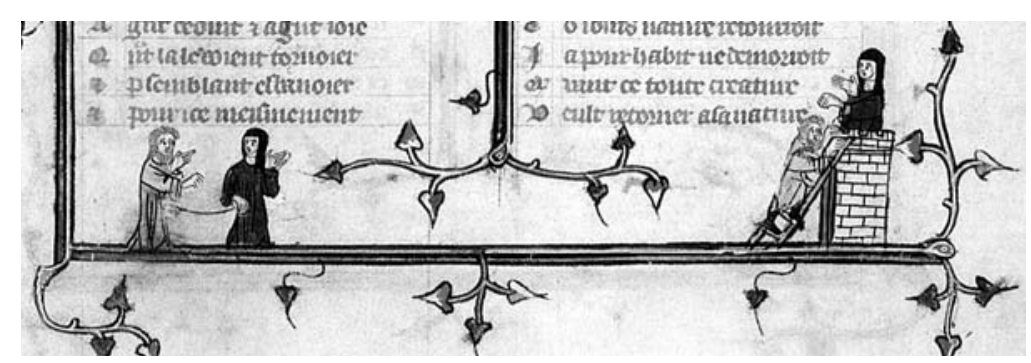

Metàfores gràfiques de les activitats libidinoses d'un frare i una monja (Roman de la rose, París, Bibliothèque nationale).

Una altra prostituta de l'Espill és una monja que té cura de l'hort i que havia tingut un passat apòstata. És un personatge típic de fabliau, una monja que ho és per força i que no té cap vocació de vida honesta i continent, sinó que és un model de depravació de costums perquè el seu comportament ha de provocar la rialla, com aquella monja que va acabar sent forçada perquè no va trencar el seu vot de silenci que apareix en un dels sermons de sant Vicent Ferrer:

Així com de la monja forçada que no volgué trencar lo vot de silenci, havet com caigué e fo pres lo castell, ço és, l'ànima. E pres-li així: que féu vot de tenir silenci, e esdevenc-se que un hom la forçava, e per no tren-

5. Tot i que el càstig més comú que s'aplicava a les mares que prostituïen les seves filles era que se'ls feia córrer per la vila nues i se les fuetejava «ab açots mortals» (Viciano 2005: 353).

6. Un document anterior a $145 \mathrm{I}$ diu «Dos dels principals jo he fet rossegar per la ciutat e squorterar» (DCVB, IX, 585, sv. «rossegar»)). car lo vot del silenci, no dix res ne parlà, sinó que deia un «hu-hu». E fo sabut per la abadessa, e reptà-la perquè no havia dit queacom; e aquesta dix que no gosà per servar silenci. Haveus com pecà. (Sanchis \& Schib 1932- 1988: III, 93; regularitzo l'ortografia)

El passatge de l'Espill fa així:

La qui te l'ort

qui dintre sta,

apostata

en lo passat:

ha prou cassat,

lo mon çerquant

he trespassant

per Çequa y Mequa,

la Vilaçequa

he Vall d'Andorra,

Volta d'en Torra

he Senta Creu,

pertot arreu,

ffins Pont Tranquat.

Al lloch sagrat

puys reçeptada,

ben castiguada,

me feu menbrant

ffos recordant

del manament

de creximent,

multiplicar

he aumentar,

lo mon onplir,

degues complir.

(Carré 2000: II, 4I72-4I96)

[La monja encarregada de l'hort que hi ha dins del convent va apostatar en el passat, i per això ha caçat força, recorrent el món i traspassant la Seca i la Meca, la Vila-seca i la Vall d'Andorra, la Volta d'en Torra i la Santa Creu, ha anat per tot arreu fins al Pont Trencat. Acollida després al lloc sagrat - on va ser ben corregida!-, em va fer membrar que havia de recordar el manament del creixement, que havia de complir allò de l'augmentar, el multiplicar-se i omplir el món.]

La monja apòstata que defensa la sexualitat amb el suport del versicle bíblic de Gn I,28 (després de crear l'home i la dona, Déu els va beneir i els va dir: «engen- 


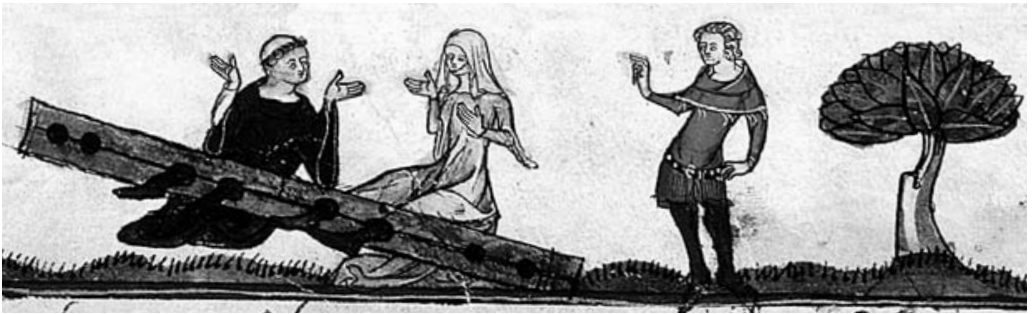

Un cavaller castiga la seva dama pel seu comportament descortès durant la confessió (Londres, British Library).

dreu i multipliqueu-vos i ompliu la terra i senyoregeula i domineu els peixos de la mar, els ocells del cel i tots els rèptils que s'arrosseguen per la terra») utilitza un argument propi dels heretges seguidors d'Epicur, el filòsof que va defensar l'amor carnal com un dels béns suprems, segons Francesc Eiximenis (Renedo 1994). Per demostrar que la monja en qüestió ha voltat molt, Jaume Roig amplia una frase proverbial, «córrer la Seca i la Meca i la Vall d'Andorra» amb topònims de la seva collita. La Seca i la Meca són els noms de dos castells propers. El primer és el castell d'Ars, anomenat la Seca i que es troba a la comarca de l'Alt Urgell. El segon és un castell andorrà, situat prop d'Ordino. Si Vila-seca i Santa Creu no es poden identificar amb exactitud ja que hi ha diversos indrets als quals correspon la nomenclatura, la Volta d'en Torra i el Pont Trencat fan referència, sense cap mena de dubte, a dos prostibuls públics de dues ciutats importants. Com hem vist més amunt, la Volta d'en Torra és un dels bordells de Barcelona. El Pont Trencat és el prostíbul d'Avinyó, la ciutat dels papes que Petrarca anomenava la Babilònia de l'oest. El bordell d'Avinyó es trobava agrupat al voltant de diversos carrers que envoltaven una placeta amb arbres (Rossiaud 1986: I3), prop del Pont Trencat que als segles XIV i XV comunicava amb la vila nova (Pansier 1979: I8I). Consta l'existència a Avinyó d'una casa de banys que duia el mateix nom (Rossiaud 1986: 14).

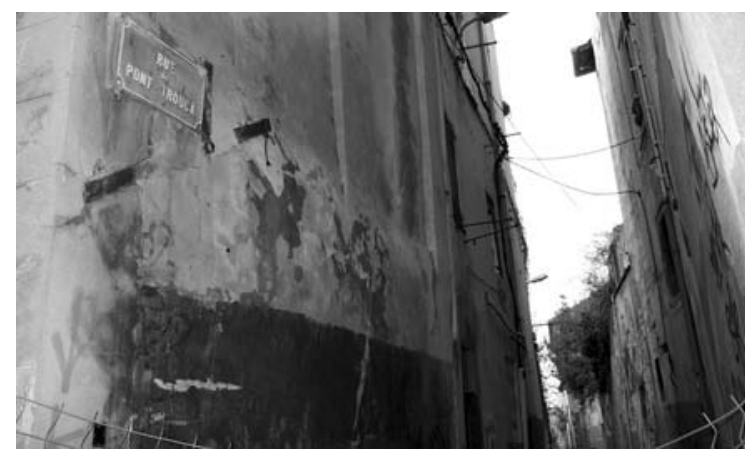

El carrer del Pont Trencat d'Avinyó, on al segle XV hi havia el prostíbul (Fotografia de Didier Boisseuil).
El tercer exemple de prostitució és metafòric. Correspon a un passatge del llibre tercer de l'Espill on s'arriben a dir veritables barbaritats contra la somera que Jesús va rebutjar cavalcar durant la seva entrada a Jerusalem el diumenge de Rams (va escollir un pollí, segons relaten els evangelis: Mt 2I, I- I I; Mc I I, II0; Lc 19,28-44; In 12, 12-19) i que simbolitza la llei vella, la llei dels jueus que és substituiida pel cristianisme:

\author{
L'asna aquella \\ que fon trobada \\ al peu lliguada \\ ha hun pinell, \\ prop lo castell \\ ple d'almuguaves \\ he de gens braves \\ moltes esquadres, \\ cullerats, lladres, \\ saltejados \\ he robados \\ -inichs contraris \\ als comissaris \\ he tots ells massa-, \\ com a baguassa \\ sodomitava \\ he fornicava \\ ab sos tacanys, \\ molts deus stranys, \\ pseudo divins, \\ asens, roçins: \\ quants hi anaven \\ la cavalcaven \\ com a publica. \\ Vench la ynica \\ coxa e manca \\ per dolor d'anca \\ he fals corter, \\ sens traginer \\ ni altra guarda, \\ sens bast, albarda, \\ collar, tifells, \\ sens cascavells, \\ pitral, ransal, \\ boç e dogual, \\ $[\ldots]$.
}

(Carré 2000: III, vv. 6654-6688) 
[La somera aquella que va ser trobada lligada al peu d'un pi petit, prop del castell ple d'almogàvers i de moltes esquadres de gent valenta, de collerats, lladres, saltejadors i robadors -inics contraris als comissaris i que tots ells són massa-, com a bagassa sodomitava i fornicava amb els seus brètols, molts déus estranys, pseudodivins, ases i rossins: tots els que hi anaven la cavalcaven com a una prostituta. La iniqua va acabar coixa i manca per culpa d'un dolor d'anca i d'un fals quarter, sense traginer ni cap altre guarda, sense bast, sense albarda, ni collar, ni picarols, ni cascavells, sense pitral, ni ronsal, boç ni dogal... .]

La somera sodomitava i fornicava amb els ases i rossins que la cavalcaven com si fos una prostituta. L'episodi és un exemple de la comicitat de l'Espill que radica en l'excés i en l'exabrupte, sí, però que també s'amaga sota un cert refinament produït per l'estil còmic, ja que el passatge conté un terme inventat per Roig que és una picada d'ullet al públic atent i subtil, capaç de captar les enginyositats retòriques que se li proposen: el verb «sodomitar», que vol dir cometre accions sodomítiques i que es fa difícil d'imaginar com podia executar-lo activament la pobra bèstia.

L'últim exemple relaciona l'erotisme amb els banys públics, que ja sabem que eren indrets vinculats amb els contactes amorosos prohibits. El protagonista i narrador de l'Espill ens informa que la seva primera esposa, la donzella, freqüentava amb excés els banys, en un passatge que té evidents connotacions sexuals:

\author{
Sovint anava \\ de nit al nou \\ bany d'en Çanou, \\ o d'en Suau; \\ en lo palau \\ de despullar \\ vereu ballar, \\ en bels tapits, \\ ahuchs, salts, crits, \\ ab ses veynes; \\ perdius, gualines, \\ pollets petits, \\ juleps, solsits, \\ ous ab gingebre, \\ los dus ab pebre, \\ grech e clarea
}

\author{
sense perea, \\ la malvesia \\ per cortesia \\ en guobellets, \\ los artalets \\ no. Is y preaven, \\ e si y ampraven \\ peguats de llambre, \\ benguhy, ambre, \\ aygues, almesch. \\ Ffeya fer fresch \\ molt çitronat, \\ carabaçat, \\ prou gingebrons, \\ he canyellons, \\ ffin tartuguat \\ hi caponat \\ en lletovari.
}

(Carré 2000: Il, w. 694-727)

[De nit, sovint anava al nou bany d'en Sanou o al d'en Suau. Al palau del despullar-se la podíeu veure ballar amb les seves veïnes damunt de belles catifes, fent aücs, salts i crits. Menjaven perdius, gallines, pollets petits, cuits en julep o estofats, ous amb gingebre i els durs amb pebre. Bevien vi grec i claret sense mandra, i la malvasia la bevien en gobelets per cortesia. Els pastissets d'ametlla no els apreciaven, però sí que hi empraven pegats de llambre, benjuí, ambre, aigües perfumades i almesc. Es feia fer molt citronat fresc, confitura de carabassa, força confits de gingebre i de canyella i un brou fi de tortuga i un de capó com a lletovari.]

Les dues cases de banys esmentades en el passatge estan ben documentades a la ciutat de València: els banys de Sanou es trobaven prop de la parròquia de Sant Llorenç, segons un document de 1380, mentre que els de Suau, en servei fins a la meitat del segle $X X$, eren coneguts com els banys de l'Almirall perquè estaven situats en el palau del mateix nom, just al darrere de la catedral (Miquel i Planas 1929-50: vol. 2, 295). Com en el famós capítol 231 del Tirant lo Blanc que descriu el ressopó i el bany de Carmesina abans de dormir per primera vegada amb el cavaller enamorat, el catàleg

7. Carmesina es menja un parell de perdius amb malvasia de Càndia i una dotzena d'ous amb canyella i sucre. 
d'aliments, vins i substàncies aromàtiques es caracteritza per les seves qualitats afrodisíaques, ben conegudes per tothom a l'Edat Mitjana. Fins i tot Ramon Llull, en el capítol 91 de la seva Doctrina pueril, exposa que per olorar ambre i almesc s'engendra la luxúria (Santanach 2005: 252). No som massa lluny del saber sexual d'una prostituta siciliana que a mitjan segle XIV estimulava els seus clients amb banys d'estufa i amb xarops confortatius:
En Vallès se gloriejava que jamai no sabé pler de fembra sinó d'aquesta, car deia que a.III. hores la nit li feia banys d'estuba e li donava a beure aixarops confortatius, així que nit hi havia haguda que.X. vegades havia hagut afer ab ella, així que dins aquells.x. dies tot l'hac xuclat e mamat e buidat, que com partim de Castell de Càller més semblava mort que viu [... ] (Cifuentes 1999: 23-24; regularitzo l'ortografia).

\section{Bibliografia}

ARCHER, Robert, i RIQUER, Isabel de (eds.), 1998: Contra las mujeres. Poemas medievales de rechazo y vituperio, Barcelona: Quaderns Crema.

ASPERTI, Stefano, 2005: «El sirventès i I'herència de Bertran de Born», Mot so razo, 4, 49-58.

Batlle, Carme i Vinyoles, Maria Teresa, 2002: Mirada a la Barcelona medieval des de les finestres gòtiques, Barcelona: Rafael Dalmau.

BLAMIRES, Alcuin (ed.), 1992: Woman Defamed and Woman Defended:An Anthology of Medieval Texts, Oxford: Clarendon Press.

CABRÉ, Miriam, 2002: «El saber de Joan Ramon Ferrer»), a Lola Badia, Miriam Cabré i Sadurní Martí (ed.), Literatura i cultura a la Corona d'Aragó (s. XIII-XV):Actes del III Col-loqui «Problemes i Mètodes de Literatura Catalana Antiga», Universitat de Girona, 5-8 de juliol de 2000), Barcelona: Curial - PAM, 227-258.

CANTAVella, Rosanna, 1992: Els cards i el llir: una lectura de l'Espill de Jaume Roig, Barcelona: Quaderns Crema.

CARRÉ, Antònia, 1994: «L'estil de Jaume Roig: les propostes ètica i estètica de l'Espills), a Lola Badia i Albert Soler (eds.), Intel·lectuals i escriptors a la baixa Edat Mitjana catalana. Barcelona: PAM - Curial, I85-2I9.

CARrÉ, Antònia (ed.), 2000: Jaume Roig, Spill, a Repertorio informatizzato dell'antica letteratura catalana (RIALC), Università di Napoli Federico II, <http://www.rialc.unina.it/>
CARRÉ, Antònia, 2002: «El rescrit de Jaume Roig i les noves rimades comediades», Lola Badia, Miriam Cabré i Sadurní Martí (ed.), Literatura i cultura a la Corona d'Aragó (s. XIII-XV):Actes del III Col-loqui «Problemes i Mètodes de Literatura Catalana Antiga», Universitat de Girona, 5-8 de juliol de 2000), Barcelona: Curial - PAM, 355-372.

CARRÉ, Antònia i CIFUentes, Lluís, en premsa: «Los baños en la literatura catalana medieval durante los siglos XIV i XV», Congreso Internacional de la Asociación Hispánica de Literatura Medieval (León, 2005).

CIFUeNTES, Lluís, I999: «Una confidència feta al notari Bartomeu de Miramat per fra Francesc, bisbe de Bisarcio: 'fembres', febres i 'desnaturament' a la Sardenya de mitjan segle XIV», en Estudis Històrics i Documents dels Arxius de Protocols, 17, 7-24.

DCVB: Antoni M. Alcover i Francesc de B. Moll, Diccionari català-valenciàbalear, Palma de Mallorca, 10 vols, 1985.

FLANDRIN, Jean Louis, 1984: La moral sexual en Occidente, Barcelona: Granica.

JuVEnAL, I96I: Sàtires, trad. de Manuel Balasch, prve., Barcelona: Fundació Bernat Metge.

MiQuel I Planas, Ramon, 1929-50: Spill o Libre de consells de Jaume Roig, poema satíric del segle XV, Barcelona: Biblioteca Catalana, 2 vols.

NarbonA, Rafael, 1992: Pueblo, poder y sexo. Valencia medieval (I 306-/ 420), València: Diputació de València.
PANSIER, Paul, 1979: Dictionnaire des Anciennes rues d'Avignon, Marsella: Laffite Repoints [ ${ }^{\mathrm{a}}$ ed. Avinyó 1930].

RENEDO, Xavier, 1994: «L'heretge epicur a Lo somni de Bernat Metge», a Lola Badia i Albert Soler (eds.), Intel/lectuals i escriptors a la baixa Edat Mitjana catalana, Barcelona: PAM - Curial, I09-I27.

RIQUER, Martí de, 1975: Los trovadores. Historia literaria y textos, 3 vols., Barcelona: Ariel.

RIQUeR, Martí de, 1986: «Las 'coplas de la panadera' en Cataluña», Philologica Hispaniensa in honorem M.Alvar, III, Madrid: Gredos, 435-450.

RosSIAUD, Jacques, 1986: La prostitución en el Medievo, Barcelona: Ariel.

SANCHIS SiVERA, Josep, i Gret SCHIB (eds), 1932-1988: Sant Vicent Ferrer Sermons, 6 vols, Barcelona: Barcino.

SANTANACH I SUÑOL, Joan (ed.), 2005: Ramon Llull, Doctrina pueril, Palma: Patronat Ramon Llull (NEORL, 7)

SERRA VILARÓ, Joan, 1962-66: Història de Cardona,Tarragona: Sugrañés.

VICIANO, Pau, 2005: «El bordell dels prohoms. El control municipal de la prostitució al Castelló del segle XV»), Anuario de estudios medievales, 35. I, 327-358.

VINYOLES, Maria Teresa, 2005: Història de les dones a la Catalunya medieval,Vic - Lleida: Eumo - Pagès. 